\title{
Age estimation by tooth/pulp ratio in canines by peri-apical X-rays: reliability in age determination of Spanish and Italian medieval skeletal remains
}

\author{
Stefano De Luca ${ }^{\mathrm{a}, *}$, Inmaculada Alemán ${ }^{\mathrm{a}}$, Francesca Bertoldi ${ }^{\mathrm{b}}$, Luigi Ferrante ${ }^{\mathrm{c}}$, Paola Mastrangelo ${ }^{\mathrm{a}}$, \\ Mariano Cingolani $^{\mathrm{d}}$, Roberto Cameriere ${ }^{\mathrm{e}}$ \\ ${ }^{a}$ Laboratory of Anthropology, Faculty of Medicine, University of Granada, 18013 Granada, Spain \\ ${ }^{\mathrm{b}}$ Dipartimento di Scienze dell'Antichità e del Vicino Oriente, University of Ca' Foscari, Venice, Italy \\ ${ }^{\mathrm{c}}$ Institute of Biochemical Biotechnologies, Faculty of Medicine, Polytechnical University of Marches, Ancona, Italy \\ ${ }^{\mathrm{d}}$ Institute of Legal Medicine, University of Macerata, Macerata, Italy \\ e AgEstimation Project, Institute of Legal Medicine, University of Macerata, Macerata, Italy
}

\section{A R T I C L E I N F O}

\section{Article history:}

Received 13 January 2010

Received in revised form

14 April 2010

Accepted 26 June 2010

\section{Keywords:}

Palaeodemography

Dental age

Secondary dentine

Pulp/tooth area

Medieval cemeteries

Spain

Italy

\begin{abstract}
A B S T R A C T
Estimation of age at death is an unavoidable step in the process of human identification, both in forensic practice and in the anthropological and palaeopathological study of skeletal remains. In several cases, in which medical or demographic records are completely lacking, a reliable estimation of the age at death becomes very important. Skeletal remains from archaeological contexts suffer from several biasing factors such as post-mortem changes, taphonomy and various burial practices depending on age, sex and social status of the deceased persons.

Currently, anthropological methods of age determination reveal several possibilities of inaccuracy. Of all the body parts used in age estimation, teeth are the least affected by any taphonomic process.

Although there are many dental methods for age at death estimation, some of them are very complex and/or destructive and they are not normally used in anthropology. However, study of the apposition of secondary dentine by examining peri-apical X-rays of canines is beginning to supply very interesting results.

The aim of this work was to test Cameriere's method on a large sample of historical subjects from several cemeteries in Spain and Italy. The Spanish sample belongs to the Medieval cemetery of La Torrecilla (Arenas del Rey, Granada) and is housed in the Laboratory of Anthropology, Faculty of Medicine, University of Granada. The Italian samples come from the Medieval cemeteries of Comacchio (Ferrara) and Castel S. Pietro (Bologna).

In order to test the reliability of Cameriere's method, age estimations of canines were compared with the mean ranges of age of the most commonly applied anthropological methods such as tooth wear changes in the pubic symphysis or the metamorphosis of the auricular surface of the ilium. Tests on these Middle Ages cemeteries produced satisfactory results, indicating that Cameriere's method is a reliable tool in determining age at death in skeletal remains of archaeological context.
\end{abstract}

Crown Copyright $\odot 2010$ Published by Elsevier Ltd. All rights reserved.

\section{Introduction}

Estimation of age at death is one of the main tasks of forensic and archaeological research, but the aims and human material of these disciplines are different.

In the forensic context, age determination is not only a prerequisite for stating that an individual has officially died; it is also the basis for investigating crimes, mass disasters or war crimes. Judicial requirements, time and the accuracy of the age range are basic factors in developing identification procedures.

Central to palaeodemography is the generation and interpretation of skeletal age distributions, as this information offers key insights into the demographic composition of a particular population and possible differential mortality based on age. Reconstruction

\footnotetext{
* Corresponding author.

E-mail address: sluca@ugr.es (S. De Luca).
}

0305-4403/\$ - see front matter Crown Copyright (c) 2010 Published by Elsevier Ltd. All rights reserved. doi:10.1016/j.jas.2010.06.034 
of mortality patterns is essential for an understanding of the living condition which human populations faced in historic ecosystems (Hoppa and Vaupel, 2002).

Age-related changes in the skeleton occur as an individual undergoes growth, development, and maturation. The appearance of age markers in an individual skeleton can vary, depending on the individual's life history. In subadults, according to age groups, stages of dental and skeletal growth and development are used to estimate age reliably (Scheuer and Black, 2000; Ubelaker, 1999). In adult human skeletal remains, in which skeletal and dental development is already complete, techniques for estimating age at death rely on degenerative skeletal changes which are much more variable and less predictable than growth sequences.

The most widespread techniques of adult age determination, according to body preservation, are based on the analysis of macroscopic characteristics of various skeletal structures (Cunha et al., 2009): the pubic symphysis (Suchey and Katz, 1998; Todd, 1921), the auricular surface of the ilium (Lovejoy et al., 1985), the sternal rib ends (Işcan and Loth, 1989) or the endo- and ectocranial sutures (Galera et al., 1998; Meindl and Lovejoy, 1985). However, these methods establish large spans of age classes and cannot yield precise results for individuals aged more than 45-50 years. In addition, these specific skeletal structures are commonly subjected to taphonomic processes and are often not recovered or are too damaged to contribute to satisfactory osteological analysis. So it becomes necessary to check the validity of more accurate methods, less biased by other factors such as the degree of agerelated information contained within specific skeletal traits, as well as sampling strategies and statistical methods used to develop age estimation methods (Baccino et al., 1991; González, 2007; Igarashi et al., 2005; Jackes, 2000; Landa et al., 2009; Roksandic et al., 2009).

Thanks to recent and relevant advances of physical anthropology, old methods have been improved and new techniques have been recently proposed. However, there is still much confusion about the standardisation of methods, procedures and statistical parameters (Cattaneo, 2007; Cunha et al., 2009; Martín de las Heras, 2005; Rosing et al., 2007). It is necessary to take into account many factors such as the context, costs, time and equipment required, the examiner's qualifications and the various states of preservation of bodies. Choice also partly depends on how accurate the age diagnosis needs to be in the case in question (Schmeling et al., 2007).

With this move towards improving existing techniques of age at death estimation, more accurate age-related changes in teeth have recently been re-examined as an alternative to skeletally based techniques. Dental structures are becoming more and more useful, because of their resistance to physical and chemical agents. They are still preserved even when most of the bones have been destroyed, mutilated or affected by other taphonomic agents (Lucy et al., 1995; Prieto, 2002).

Several proposed dental methods are based on macroscopic, microscopic and biochemical analysis of teeth. Study of dental wear is certainly the easiest and fastest, but also the least accurate (Brothwell, 1989; Kim et al., 2000). Other methods imply partial destruction of the tooth, and seem to be very complicated and expensive to be applied on a large scale (Gustafson, 1950; Martín de las Heras et al., 1999; Ohtani, 1991; Renz and Radlanski, 2006).

One of the best-known features of ageing is the reduction in size of the pulp chamber, caused by the continual secretion of dentinal matrix by odontoblasts (physiological secondary dentinogenesis) (Solheim, 1992). Dentine is a living tissue containing odontoblasts which form the tooth and which, during a person's lifetime, for both physiological and pathological reasons, deposit layers of secondary dentine which gradually obliterates the pulp chamber (Bodecker, 1925; Vasiliadis et al., 1983).
The mean rate of increasing dentinal thickness has been found to be $6.5 \mu \mathrm{m}$ per year for the crown and $10 \mu \mathrm{m}$ per year for the root. The effect of continuous dentine deposition is the progressive increase in dentinal thickness by $0.45 \mathrm{~mm}(17.1 \%)$ and $0.60 \mathrm{~mm}$ (24.3\%) in the crown and root areas, respectively. The pattern of secondary dentine deposition varies with tooth type. As regard sex, no statistically significant differences are observed (Murray et al., 2002).

In 1925, Bodecker (1925) ascertained that the apposition of secondary dentine was correlated to chronological age. Detailed studies of the pattern and rate of secondary dentine apposition in maxillary anterior teeth were performed by Philippas and Applebaum $(1966,1967,1968)$ but without the aim of estimating age at death. Secondary dentine deposition was included in the method pioneered by Gustafson (1950), in which dentine transparency and secondary dentine values showed the highest correlation with age. Currently, the apposition of secondary dentine may provide a useful tool in age estimation in adults (Cunha et al., 2009; Drusini et al., 1997).

Secondary dentine has been studied by several methods: examples are sectioning and X-rays (Kvaal and Solheim, 1994; Paewinsky et al., 2005; Philippas, 1961) and peri-apical X-rays of canines. Both methods reduce possible errors caused by magnification and distortion of X-rays and provide better image quality. Cameriere et al. (2007a,b) studied the relationship between the age at death and the ratio of the pulp/tooth area in peri-apical X-rays of upper and lower canines of several individuals in an identified Italian osteological collection.

Reliability is the degree to which a method produces the same results when it is used at different times, either by multiple observers or by the same observer. It can be tested by conducting inter-observer or intra-observer variation studies to determine error rates. Low inter-observer variation (or error) indicates high reliability (Adams and Byrd, 2002).

The main aim of this paper was to test the reliability of Cameriere's method in three Medieval samples of unknown age at death, from Spain and Italy, and to examine its use in order to estimate the age of skeletal remains from archaeological contexts. This method, which was tested in a small sample of 9 identified mummies (14th century) from the Basilica of S. Domenico Maggiore (Cameriere et al., 2006), one of the largest and most important churches in Naples (Italy), is now tested for the first time on a large Medieval sample from various archaeological sites.

Another aim of the work was to compare results obtained by various ageing methods. Many ageing techniques have demonstrated a general trend of over-ageing younger individuals and under-ageing older ones (Aykroyd et al., 1997). Taking this into account, we focused attention on some of the factors which typically confound studies of historically extant populations. First of all, differential preservation of samples is a major source of bias in palaeodemographic parameters (Bell et al., 1996; Haglund and Sorg, 2002). Secondly, these data can determine which of these methods tend to estimate high ages among all the procedures, and shows to what extent age estimates, based upon various ageing criteria, can vary in differing conditions of conservation (Wittwer-Backofen et al., 2008).

\section{Materials and methods}

The Spanish sample dates to the Middle Ages and consists of 30 individuals, 14 males and 16 females, from one of the most important Medieval Islamic cemeteries in Spain, La Torrecilla (Arenas del Rey, Granada) (11th-14th centuries). This cemetery is located north of the Bermejales swamp, in the southern part of the province of Granada (Spain). Drs. Arribas and Riu conducted two 
brief excavations in 1968 and 1969. Later works were carried out in 1974 and 1976 (du Souich, 1979). Currently, the skeletons are housed in the Laboratory of Anthropology, Faculty of Medicine, University of Granada (Spain). The condition of the bone remains is excellent; especially skulls and jaws which, despite the antiquity of the finds, have been very well preserved. A subsample of 113 upper and lower canines was analysed.

The Italian sample consists of the individuals buried in the Medieval cemeteries of Comacchio (Ferrara) and Castel San Pietro (Bologna) (Bertoldi, 2009; Librenti, 2003). These samples were composed of 43 individuals, 21 males, 20 females and two indeterminate, dating from the early Middle Ages to the Modern Age (16th-17th century A.D.). The Italian samples, especially those from Comacchio, are poorly preserved, due to bone diagenesis, soil erosion, mechanical destruction, and poor excavation techniques.

It is important to note that the selected samples are not representative of the Medieval Spanish and Italian populations as a whole. Therefore, neither the age nor sex distribution of these samples should be interpreted as population-specific. Sex was estimated by osteological characteristics according to Ferembach et al. (1980). The selected nomenclature to classify the canines is that proposed by the I.D.F (International Dental Federation).

Depending both on the state of preservation of each skeleton and the observer's experience, several methods based on the macroscopic changes in various skeletal structures have been employed: endo- and ectocranial sutures (Galera et al., 1998; Meindl and Lovejoy, 1985), dental wear (Brothwell, 1989; Lovejoy, 1985), structure of the pubic symphysis (Suchey and Katz, 1998; Todd, 1921), changes in the auricular surface of the ilium (Lovejoy et al., 1985), metamorphosis of the sternal rib ends (Ișcan and Loth, 1989), degree of fusion of the sacral vertebrae (Belcastro et al., 2008) and, lastly, the degree of fusion of the epiphysis of the long bones (Mays, 2003).

In addition, in all samples, the age at death of each individual was estimated by radiographic evaluation of secondary dentine of the upper and lower canines (Cameriere et al., 2007a,b). Canines without significant pathologies were chosen and, if both were present, both were studied.

Intra-oral peri-apical digital radiographs were taken on a KODAK RVG 6100 Digital Radiography System with the paralleling technique, with a $10 \mathrm{ma}$ exposure, time of $0.05 \mathrm{~s}$ at $70 \mathrm{Kpv}$. Due to technological advances with the optical plate and scintillator, all size sensors have increased sensitivity, which allows researchers to decrease the radiation dose. The teeth were X-rayed both isolated and in situ, depending on the state of conservation of each skeleton and on the possibility of extracting them without damage (Figs. 1 and 2).

The radiographic images were saved as high resolution in JPEG size for further image analysis (Fig. 3). Following Cameriere et al. $(2007 a, b)$, the images of the canines were processed with a computer-aided drafting program (ADOBE Photoshop CS4) (Fig. 4). A minimum of 20 points from each tooth outline and 10 points from each pulp outline were identified and connected with the line tool, also on the Draw Toolbox, and the area of both tooth and pulp were ascertained.

Age estimation was made by applying the three linear regression equations proposed by Cameriere et al. (2007a,b) for the upper canine (1), lower canine (2), and for both canines (3):

Upper canine : Age $=99.937-532.775(x 1)$

Lower canine : Age $=89.456-461.873(\mathrm{x} 2)$

Both canines : Age $=114.624-431.183(\mathrm{x} 1)-456.692(\mathrm{x} 2)$

$$
+1798.377(\mathrm{x} 1)(\mathrm{x} 2)
$$

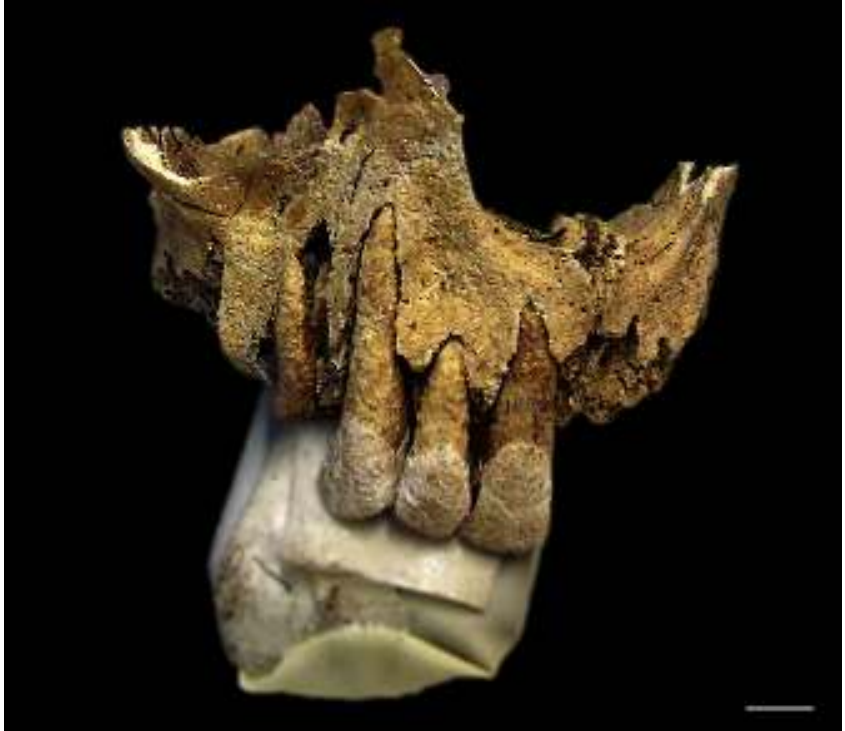

Fig. 1. Upper right canine of TOR 254 before peri-apical X-ray. Observe the good preservation of the teeth of this female subject.

$\mathrm{x} 1$ and $\mathrm{x} 2$ respectively represent the pulp/tooth area ratio in upper and lower canines.

All measurements were carried out by two different observers with ample experience of this method. To test intra-observer and inter-observer reproducibility, a random sample of 50 peri-apical $\mathrm{X}$-rays was re-examined after an interval of three weeks. Intraobserver and inter-observer reproducibility of measurements was studied by Pearson's concordance-correlation coefficient.

The anthropological age (AA) represents the mean age range calculated taking into account all the age intervals obtained by applying all the studied methods of age determination. The anthropological age (AA) and dental canine age (DA) were defined as matching if the estimate of the age at death obtained with Eqs. (1)-(3) belonged to the mean range of the age at death estimated on the same skeletons using anthropological methods.

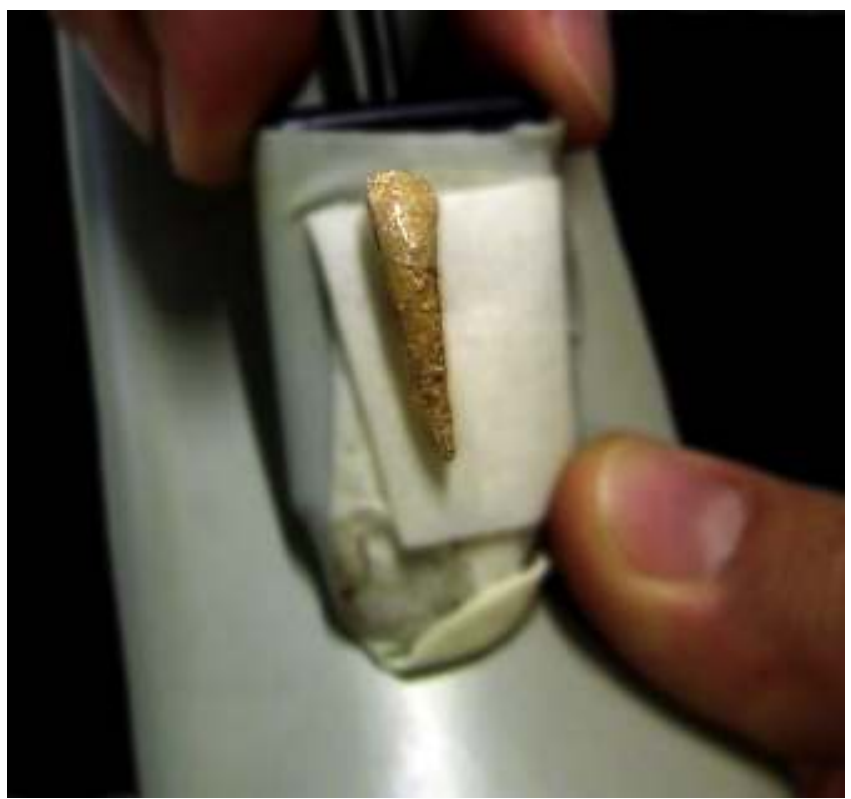

Fig. 2. Lower left canine of TOR 249 before peri-apical X-rays. In this case the tooth has been extracted, without damage, before X-raying the sample. 


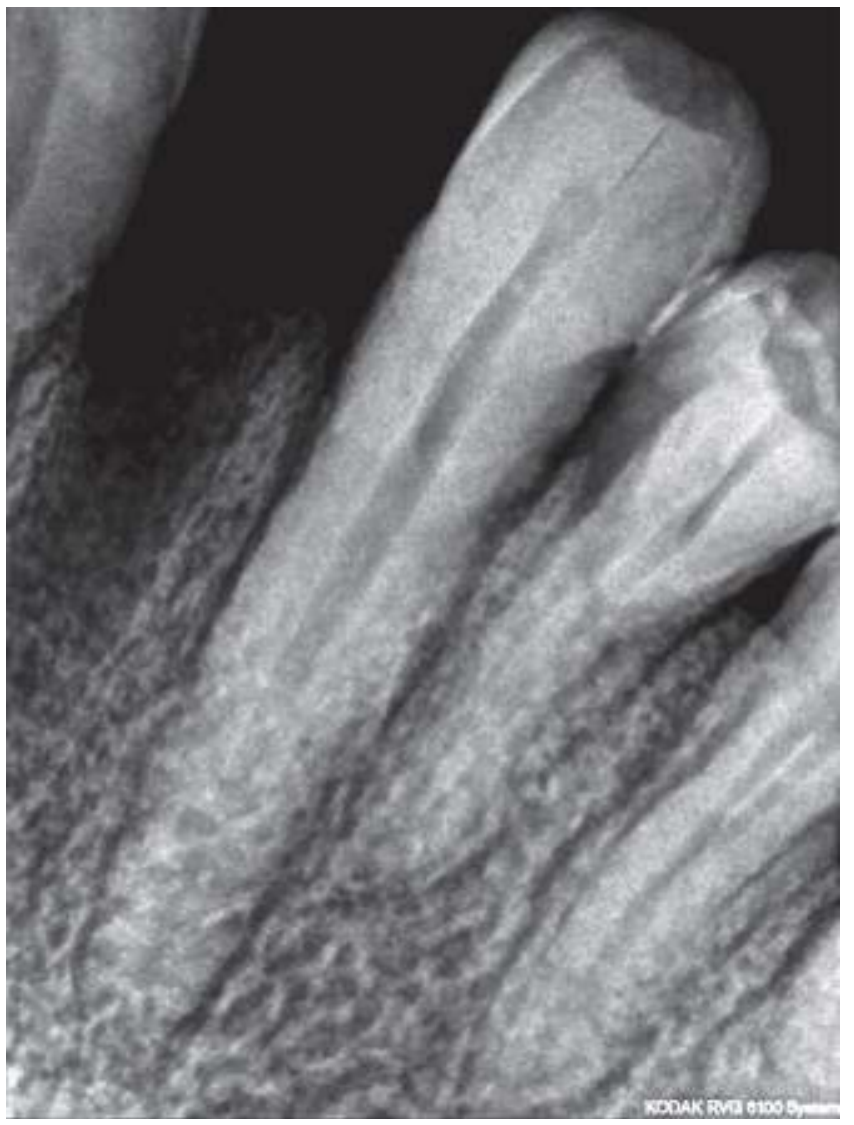

Fig. 3. Detail from a peri-apical X-rayed image of the upper right canine of TOR 294 . Observe the great contrast and definition of the image thanks to digital radiography system.

\section{Results}

As regards radiographic study of the samples, there were no statistically significant intra-observer and inter-observer differences between the paired sets of measurements carried out on the re-examined peri-apical digital X-rays. The Pearson test also revealed that there were no significant differences $(p<0.01)$.

Depending on the method applied, the percentage of skeletons deemed suitable for analysis varied between $11 \%$ and $85 \%$, reflecting the differential preservation of skeletal elements and the influence of taphonomic processes after burial. In addition, 85\% of the individuals were analysed according to the degree of dental wear; $63 \%$ by examining other anthropological indicators of age such as degree of fusion of the sacral vertebrae (20.4\%) or morphological changes in the pubic symphysis (36.9\%). However, $100 \%$ of the canines were still intact, and all of them were analysed by Cameriere's method. This reflects the importance of teeth in identification procedures in which, for incomplete or greatly deteriorated specimens, study of dental characteristics may often be the sole resource for age estimation. Table 1 lists the number of analysed individuals according to type of age estimation methods. Table 2 lists the number of subjects aged respectively according to Cameriere's method (DA), Brothwell's method (WA) and other anthropological indicators of age (AA).

Table 3 shows the actual ranges of age estimates given by the various methods for Italian samples (CSP and COM) and Table 4 those for the Spanish sample (TOR). Anthropological age represents the mean age range achieved by the application of the conventional anthropological techniques and it reflects the individual variability of the specific traits in the reference sample. Dental canine age was calculated by the study of the apposition of secondary dentine according to Cameriere et al. (2007a,b), and it was indicated with a precision of 0.1 years. The last column in Table 4 lists the mean ranges of the minimum and maximum values of age at death, calculated by applying anthropological methods. The mean age ranges of all individual age estimates for a specific method vary from 3 to 12 years and reach a maximum of 47 years.

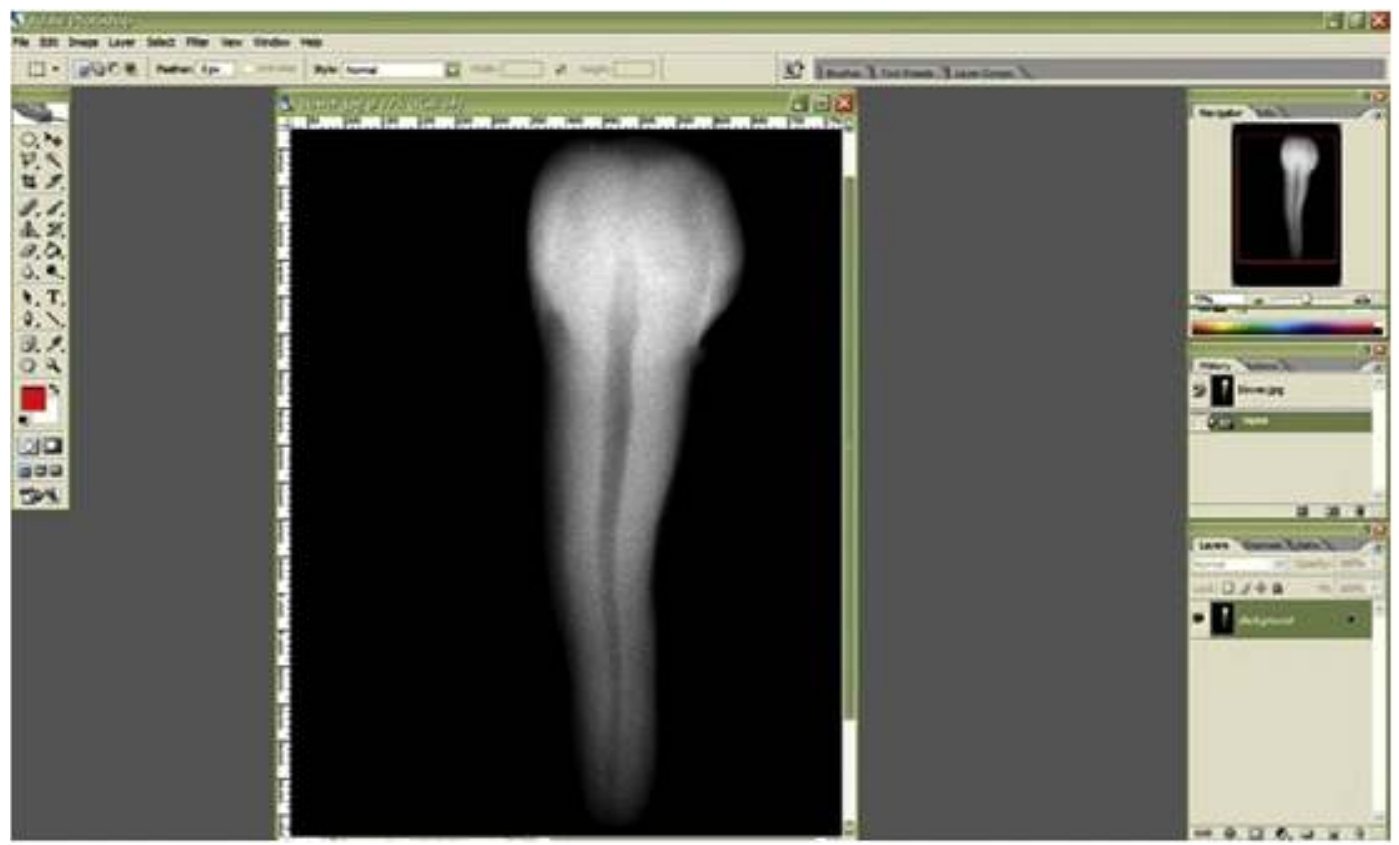

Fig. 4. The radiographic image of the canine has been processed using a computer-aided drafting program (ADOBE Photoshop CS4), before measuring pulp and tooth areas with the line tool. 
This is indicative of a poorly preserved skeleton for which not all traits could be properly assessed in each case. The width of each range may vary significantly, depending on the number of traits, their consistency, and other factors, as can be seen in the ranges of minimum and maximum values of age at death and three individuals (TOR 225, 252 and 265) for which the maximum age limit was not calculated.

In the Spanish sample, the dental canine age was over-estimated in only three individuals (TOR 220, 269, 314); of these, only one was over-estimated by more than 4 years (TOR 269). However, when the minimum and the maximum values of the age ranges are considered, the results obtained by Cameriere's method clearly fit the same ranges. Table 5 emphasises the differences which occur in the obtained mean ranges of age at death when different procedures and dental canine ages are applied. In addition, Table 5 lists all the applied methods for age determination used in the Spanish sample, including the method of Belcastro et al. (2008). This method does not stress significant differences, but always considers the impossibility of correct age determination by means of data from the sacrum, for mature and senile subjects. In fact, although Belcastro's technique suggests that incompletely fused sacra can help in distinguishing young adults (20-34 years) from old ones ( 40 years older), it can only be applied in the case of adult subjects with incomplete fusion of the sacral vertebrae. As regards Brothwell's (1989) method, it is not possible to observe any significant differences in the Spanish sample, except in the case of individual TOR 269, a female subject, in which the deposition of secondary dentine demonstrated an over-estimated age at death of several years. However, this result was consistent with the method of Isscan and Loth (1989) which, although very difficult to execute in living individuals (Dedouit et al., 2008), can be very useful in an archaeological context. However, we note two biases in this method: recovery and identification of the fourth rib in an archaeological situation may sometimes be very complicated and it apparently depends much on activity patterns. Of the methods listed in Table 5, that based on the degree of fusion of the humeral head matches dental canine age, except in three cases: TOR 233, in which dental age was over-estimated but consistent with results from the analysis of the fusion of iliac crest; TOR 252, in which dental canine age was lower but matched the age estimated by dental wear; and TOR 314, in which the over-estimation of dental canine age matched, however, the age indicated by analysis of the pubic symphysis (Suchey and Katz, 1998; Todd, 1921).

Regarding the Italian samples from Comacchio (Ferrara) and Castel San Pietro (Bologna), almost all analysed by study of dental wear, due to their high fragmentation, show less reliable anthropological age compared with dental canine age. However, taking into account all the macroscopic skeletal structures, and especially the pubic symphysis, dental canine age matches the anthropological age ranges in $70 \%$ of cases, with no more than 5 years of discrepancy. When only dental wear age was taken into account, the age spans of anthropological diagnosis becomes larger and less accurate. Although dental wear was one of the most frequently used methods in these samples, it is usually regarded as one of the most unreliable methods for estimating age at death. Older ages normally considered in the age span " 45 or 50 +" find more accurate diagnosis through application of dental canine age.

Table 6 presents age results for the samples from Castel San Pietro (Bologna) and Comacchio (Ferrara). The last column in Table 6 lists the mean ranges of the minimum and maximum values of age at death, calculated by applying analysis of dental wear and pubic symphysis. The mean age ranges of all individual age estimates for a specific method vary from 1 to 10 years. The Suchey and Katz (1998) method and Todd's (1921) method are more accurate for ageing individuals between 17 and 40 years old and, also, their

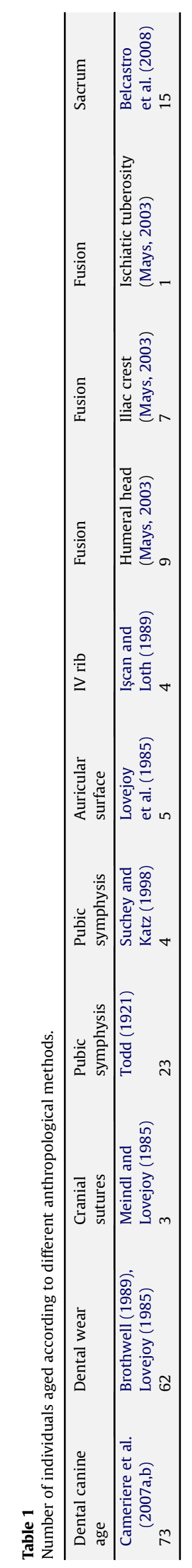


Table 2

Number of subjects aged according to Cameriere's method, Brothwell dental wear and other anthropological techniques.

\begin{tabular}{lll}
\hline $\begin{array}{l}\text { Dental canine age } \\
\text { (Cameriere et al., 2007a,b) }\end{array}$ & $\begin{array}{l}\text { Dental wear age } \\
\text { (Brothwell, 1989) }\end{array}$ & $\begin{array}{l}\text { Anthropological } \\
\text { age }\end{array}$ \\
\hline 73 & 62 & 46 \\
\hline
\end{tabular}

application is simple. However, this technique presents some disadvantages: sex and ancestry are prerequisites, and the pubic symphysis is frequently damaged in these ancient skeletons.

Tables 5 and 6 show how various methods of age determination tend to be more reliable for younger individuals and much less reliable for older ones, especially in cases of highly fragmented remains. Note that all age ranges are limited to a specific trait or set of traits, documenting the applicability of a specific ageing trait to a specific skeletal sample, depending on the observer's experience and the state of preservation. In addition, these data confirm the fact, well-known in the anthropological literature, that a small degree of error is predominantly found in younger individuals, whereas a lower degree of overlap is observed in older individuals, whose mean ages fall between 40 and 60 years of age.

Table 3

Mean ranges of anthropological age and dental canine age for Italian samples.

\begin{tabular}{|c|c|c|c|c|}
\hline Individual & Sex & $\begin{array}{l}\text { Anthropological } \\
\text { age (mean age } \\
\text { range) }\end{array}$ & $\begin{array}{l}\text { Dental } \\
\text { canine age }\end{array}$ & $\begin{array}{l}\text { Range } \\
\text { (maximum and } \\
\text { minimum) }\end{array}$ \\
\hline CSP 1 & M & $\sim 40$ & 39 & $35-45$ \\
\hline CSP 2 & $\mathrm{~F}$ & $17-25$ & 24.1 & $17-25$ \\
\hline CSP 4 & $\mathrm{~F}$ & $17-25$ & 24.2 & $17-25$ \\
\hline CSP 5 & M & 30-35 & 30.6 & 30-45 \\
\hline CSP 16 & $\mathrm{~F}$ & $25-35$ & 29.6 & $25-35$ \\
\hline CSP 17 & $\mathrm{~F}$ & $17-25$ & 19.2 & $17-25$ \\
\hline CSP 18 & $\mathrm{~F}$ & $25-35$ & 40.1 & $25-35$ \\
\hline CSP 20 & $\mathrm{~F}$ & $17-25$ & 21.1 & $17-25$ \\
\hline CSP 21a & M & $17-25$ & 18.4 & $17-25$ \\
\hline CSP 28 & M & $\sim 35$ & 40.8 & $30-35$ \\
\hline CSP 35 & M & $\sim 35$ & 45.7 & $30-35$ \\
\hline CSP 42 & $\mathrm{~F}$ & $35-45$ & 45.3 & $35-45$ \\
\hline CSP 46 & M & $45-50+$ & 56.5 & $45-55$ \\
\hline CSP 51 & $\mathrm{~F}$ & $25-35$ & 37.2 & $25-35$ \\
\hline CSP 54 & M & $25-30$ & 26.2 & $25-30$ \\
\hline CSP 70 & $\mathrm{~F}$ & $35-45$ & 54.2 & $33-45$ \\
\hline CSP 90 & M & $17-25$ & 20.2 & $17-25$ \\
\hline CSP 93 & $\mathrm{~F}$ & $17-25$ & 21.3 & $17-25$ \\
\hline CSP 115 & M & $33-45$ & 62.2 & $33-35$ \\
\hline CSP 161 & $\mathrm{~F}$ & $33-45$ & 56.2 & $33-45$ \\
\hline COM 6 & $\mathrm{~F}$ & $17-25$ & 21 & $17-25$ \\
\hline COM 34 & $\mathrm{~F}$ & $33-45$ & 45.3 & $33-45$ \\
\hline COM 40 & M & $33-45$ & 50.1 & $33-45$ \\
\hline COM 41 & M & $17-25$ & 23.9 & $17-25$ \\
\hline COM 43 & $\mathrm{~F}$ & $45+$ & 57.4 & $45-55$ \\
\hline COM 50 & $\mathrm{~F}$ & $\sim 45$ & 51.6 & $35-45$ \\
\hline COM 51 & M & $\sim 35$ & 42.2 & $25-40$ \\
\hline COM 52 & $\mathrm{~F}$ & $33-45$ & 48.7 & $33-45$ \\
\hline COM 56 & M & $45+$ & 52.2 & $45-55$ \\
\hline COM 59 & M & $33-45$ & 45.8 & $33-45$ \\
\hline COM 67 & M & $30-35$ & 27.9 & $25-35$ \\
\hline COM 76 & M & $45-50+$ & 50.7 & $45-55$ \\
\hline COM 77 & M & $\sim 30$ & 41.7 & $27-30$ \\
\hline COM 87 & $\mathrm{~F}$ & $33-45$ & 41.5 & $33-45$ \\
\hline СOM 89 & $\mathrm{~F}$ & $17-25$ & 20.3 & $25-35$ \\
\hline COM 90 & M & $33-45$ & 33.8 & $25-35$ \\
\hline COM 92 & M & $33-45$ & 34.9 & $33-45$ \\
\hline COM 110 & M & $33-45$ & 42.1 & $33-45$ \\
\hline COM 129 & $\mathrm{~F}$ & $33-45$ & 50.2 & $33-45$ \\
\hline COM 134 & $\mathrm{~F}$ & $17-25$ & 19.6 & $17-25$ \\
\hline COM 139 & M & $\sim 30$ & 27.5 & $33-45$ \\
\hline US 1349 & $?$ & $33-45$ & 43 & $33-45$ \\
\hline US $1845-2$ & $?$ & $33-45$ & 42 & $33-45$ \\
\hline
\end{tabular}

Table 4

Mean ranges of anthropological age and dental canine age for Spanish sample.

\begin{tabular}{|c|c|c|c|c|}
\hline Individual & Sex & $\begin{array}{l}\text { Anthropological } \\
\text { age (mean age } \\
\text { range) }\end{array}$ & $\begin{array}{l}\text { Dental } \\
\text { canine age }\end{array}$ & $\begin{array}{l}\text { Range } \\
\text { (maximum and } \\
\text { minimum) }\end{array}$ \\
\hline TOR 204 & M & $25-30$ & 26.5 & $25-30$ \\
\hline TOR 207 & M & $21-26$ & 21 & $17-30$ \\
\hline TOR 214 & M & $18.5-25$ & 22 & $17-25$ \\
\hline TOR 216 & $\mathrm{~F}$ & $23-27$ & 25.7 & $21-30$ \\
\hline TOR217 & $\mathrm{F}$ & $18-22$ & 22 & $18-23$ \\
\hline TOR 218 & $\mathrm{~F}$ & $26-32$ & 32 & $23-34$ \\
\hline TOR 220 & $\mathrm{~F}$ & $27.5-32$ & 33.7 & $25-34$ \\
\hline TOR 222 & M & $18-22$ & 21.5 & $18-25$ \\
\hline TOR 225 & $\mathrm{~F}$ & $39-64$ & 63 & $39-64$ \\
\hline TOR 228 & $\mathrm{~F}$ & $18-23$ & 22 & $18-24$ \\
\hline TOR 229 & $\mathrm{~F}$ & $42-87$ & 47 & $42-87$ \\
\hline TOR 231 & M & $28-32$ & 31 & $26-34$ \\
\hline TOR 233 & $\mathrm{~F}$ & $18.5-23.5$ & 23 & $17-25$ \\
\hline TOR 234 & M & $34-42$ & 35.6 & $33-45$ \\
\hline TOR 235 & M & $40-45$ & 45 & $40-45$ \\
\hline TOR 237 & M & $28-33$ & 31 & $25-35$ \\
\hline TOR 249 & M & $43-55$ & 54 & $43-55$ \\
\hline TOR 251 & $\mathrm{~F}$ & $19-22$ & 20 & $17-24$ \\
\hline TOR 252 & M & $21-27$ & 24 & $17-30$ \\
\hline TOR 254 & $\mathrm{~F}$ & $25-32.5$ & 27.7 & $25-35$ \\
\hline TOR 255 & M & $25-32$ & 29.9 & $25-35$ \\
\hline TOR 265 & M & $41-62$ & 51 & $32-65$ \\
\hline TOR 267 & $\mathrm{~F}$ & $29-38$ & 33.7 & $25-42$ \\
\hline TOR 269 & $\mathrm{~F}$ & $29-38$ & 42 & $25-42$ \\
\hline TOR 277 & $\mathrm{~F}$ & $17-24$ & 20 & $17-25$ \\
\hline TOR 291 & $\mathrm{~F}$ & $18-23$ & 23 & $17-25$ \\
\hline TOR 293 & $\mathrm{~F}$ & $18.5-25$ & 25 & $17-25$ \\
\hline TOR 294 & M & $26-32$ & 31.2 & $25-35$ \\
\hline TOR 301 & M & $26-32$ & 31 & $25-35$ \\
\hline TOR 314 & $\mathrm{~F}$ & $18-25$ & 26 & $17-29$ \\
\hline
\end{tabular}

The mean ranges of anthropological age were compared with dental canine age in the Figs. 5 and 6. The values of both Spanish and Italian samples are graphically represented to verify if dental canine age matched anthropological age. The anthropological age (AA), in all three samples, and dental canine age (DA) were concordant in $89 \%$ of cases. As expected, the data obtained by applying Cameriere's method overlapped more than 50\% with those of the other anthropological methods.

\section{Discussion}

As Maples (1989) states, age estimation of skeletal remains is ultimately "an art, not a precise science". Next to sex, age is an essential basic biological parameter which facilitates the identification of human remains in forensic and palaeodemographic contexts (Komar and Buikstra, 2008). Due to the inherent challenges in ageing and the need for better understanding of age estimates from adult skeletons, forensic anthropologists must constantly develop and test techniques for age estimation, mostly drawing on samples of known age at death.

In contrast to forensic anthropology, palaeodemography focuses on the construction of population profiles. This particular field has undergone its own critiques as regards standardisation of techniques and understanding error rates when constructing population profiles from unidentified skeletal remains. The correct interpretation of age distributions has been at the centre of intense debate, because it relies on age estimation in the absence of written records (Kemkes-Grottenthaler, 2002; Konigsberg and Frankenberg, 2002; Wood et al., 1992).

The results from the present work contribute to the discussion about factors which can influence age estimates made on the basis of various anthropological and dental methods. Interpreting the above tables and graphs, we note that different areas of the 
S. De Luca et al. / Journal of Archaeological Science xxx (2010) 1-11

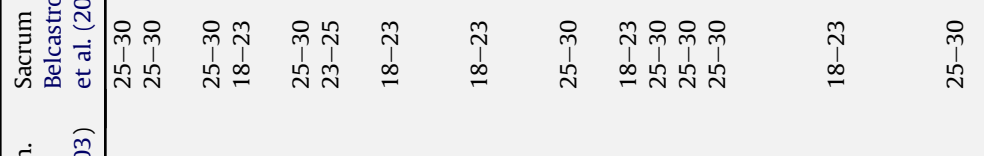

(

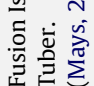

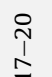

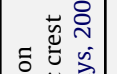

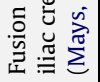

$\stackrel{i}{i} \stackrel{4}{4}$

$\begin{array}{lll}\stackrel{4}{N} & \stackrel{4}{N} & \stackrel{4}{N}\end{array}$

$\stackrel{4}{\sharp}$

$\sim$

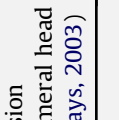

กิก ส กิก ส

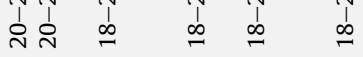

$\stackrel{+}{\sim}$

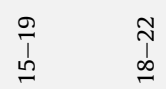

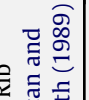

$\geq$ 芯

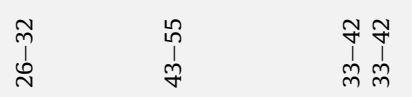

흥

离

灵弯要

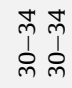

$\begin{array}{ll}m & \text { m } \\ \stackrel{m}{1} & \text { pे }\end{array}$

8

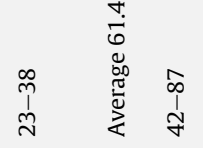

ஜे शे ?

$\stackrel{m}{i}+$

위ำ

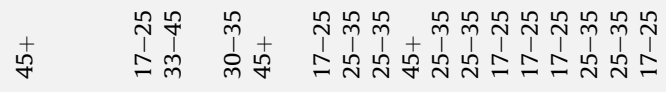

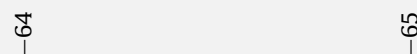

ळे

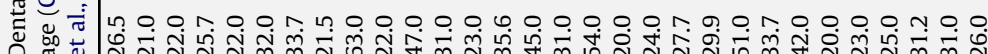


Table 6

Age at death of the individuals of the Italian samples and applied methods. Other anthropological indicators of age, such as the degree of fusion of the epiphysis of the long bones, are indicated.

\begin{tabular}{|c|c|c|c|c|c|c|}
\hline Individual & Sex & $\begin{array}{l}\text { Dental canine } \\
\text { age,Cameriere } \\
(2007 a, b)\end{array}$ & $\begin{array}{l}\text { Dental wear } \\
\text { Brothwell (1989) }\end{array}$ & $\begin{array}{l}\text { Pubic symphysis } \\
\text { Todd (1921); } \\
\text { Suchey and } \\
\text { Katz (1998) }\end{array}$ & Other indicators of age & $\begin{array}{l}\text { Range (máximum } \\
\text { and mínimum) }\end{array}$ \\
\hline CSP 1 & $\mathrm{M}$ & 39.0 & $33-45$ & $39-44$ & & $33-45$ \\
\hline CSP 2 & $\mathrm{~F}$ & 24.1 & $17-25$ & $22-24$ & Ilium about to fuse with the ischium & $17-24$ \\
\hline CSP 4 & $\mathrm{~F}$ & 24.2 & $17-25$ & & & $17-25$ \\
\hline CSP 5 & M & 30.6 & $33-45$ & $30-35$ & & $30-45$ \\
\hline CSP 16 & $\mathrm{~F}$ & 29.6 & $25-35$ & & & $25-35$ \\
\hline CSP 17 & $\mathrm{~F}$ & 19.2 & $17-25$ & $18-19$ & Head of the femur just fused to the diaphysis & $17-25$ \\
\hline CSP 18 & $\mathrm{~F}$ & 40.1 & $25-35$ & & Medial end of the clavicle shows traces of fusion & $25-35$ \\
\hline CSP 20 & $\mathrm{~F}$ & 21.1 & $17-25$ & & Head of the humerus still unfused & $17-25$ \\
\hline CSP 21a & M & 18.4 & $17-25$ & $18-19$ & Ilium about to fuse with the ischium & $17-25$ \\
\hline CSP 28 & M & 40.8 & $30-35$ & & Medial end of the clavicle shows traces of fusion & $30-35$ \\
\hline CSP 35 & M & 45.7 & $30-35$ & & & $30-35$ \\
\hline CSP 42 & $\mathrm{~F}$ & 47.3 & $33-45$ & & & $33-45$ \\
\hline CSP 46 & M & 56.5 & $45+$ & $50+$ & & $45-55$ \\
\hline CSP 51 & $\mathrm{~F}$ & 37.2 & $25-35$ & & Medial end of the clavicle shows traces of fusion & $25-35$ \\
\hline CSP 54 & M & 26.2 & $25-30$ & & Medial end of the clavicle shows traces of fusion & $25-30$ \\
\hline CSP 70 & $\mathrm{~F}$ & 54.2 & $33-45$ & & & $33-45$ \\
\hline CSP 90 & M & 20.2 & $17-25$ & $18-19$ & Iliac crest and ischiatic tuberosity just fused & $17-25$ \\
\hline CSP 93 & $\mathrm{~F}$ & 21.3 & $17-25$ & $20-21$ & Ilium, ischium and pubis are still unfused & $17-25$ \\
\hline CSP 115 & M & 62.2 & $33-45$ & & & $33-45$ \\
\hline CSP 161 & $\mathrm{~F}$ & 56.2 & $33-45$ & & & $33-45$ \\
\hline COM 6 & $\mathrm{~F}$ & 21.0 & $17-25$ & $22-24$ & Medial end of the clavicle shows traces of fusion & $17-25$ \\
\hline COM 34 & $\mathrm{~F}$ & 46.3 & $33-45$ & & & $33-45$ \\
\hline COM 40 & M & 49.8 & $33-45$ & & & $33-45$ \\
\hline COM 41 & M & 23.9 & $17-25$ & $22-24$ & Medial end of the clavicle still unfused & $17-25$ \\
\hline COM 43 & $\mathrm{~F}$ & 57.4 & $45+$ & & Several AM losses of teeth, abscesses, periodontitis & $45-55$ \\
\hline COM 50 & $\mathrm{~F}$ & 51.6 & $33-45$ & $39-44$ & Almost complete obliteration of cranial sutures & $33-45$ \\
\hline COM 51 & M & 42.2 & $25-35$ & $35-39$ & & $25-39$ \\
\hline COM 52 & $\mathrm{~F}$ & 48.7 & $33-45$ & & & $33-45$ \\
\hline COM 56 & M & 52.2 & $45+$ & & & \\
\hline COM 59 & M & 45.8 & $33-45$ & & Several AM losses of teeth & $33-45$ \\
\hline COM 67 & M & 27.9 & $25-35$ & $30-35$ & & $25-35$ \\
\hline COM 76 & M & 50.7 & $45+$ & $44-50$ & Several AM losses of teeth, abscesses, periodontitis & \\
\hline COM 77 & M & 41.7 & $25-35$ & $27-30$ & Medial end of the clavicle shows traces of fusion & $25-35$ \\
\hline COM 87 & $\mathrm{~F}$ & 41.5 & $33-45$ & & & $33-45$ \\
\hline COM 89 & $\mathrm{~F}$ & 20.3 & $25-35$ & & & $25-35$ \\
\hline COM 90 & M & 33.8 & $25-35$ & & Medial end of the clavicle shows traces of fusion & $25-35$ \\
\hline COM 92 & M & 34.9 & $33-45$ & & & $33-45$ \\
\hline COM 110 & M & 42.1 & $33-45$ & & & $33-45$ \\
\hline COM 129 & $\mathrm{~F}$ & 49.9 & $33-45$ & & & $33-45$ \\
\hline COM 134 & $\mathrm{~F}$ & 19.6 & $17-25$ & $20-21$ & Erupting M3, iliac crest about to fuse & $17-25$ \\
\hline COM 139 & M & 27.5 & $33-45$ & & & $33-45$ \\
\hline COM US 1349 & $?$ & 43.0 & $33-45$ & & & $33-45$ \\
\hline COM US $1845-2$ & $?$ & 42.0 & $33-45$ & & & $33-45$ \\
\hline
\end{tabular}

skeleton age differently and independently to the extent that both comparison of individual age estimates and the age ranges achieved by different methods and the respective age at death distributions show significant differences. This is of great interest in cases when the remains are in differing states of preservation or when not all the age indicators can be analysed. This has a major influence on the application of well-known ageing methods to historical skeletal collections, in which taphonomic processes, individual variability and pathologies can all influence the applicability of several ageing techniques.

Firstly, poor preservation often makes age determination difficult and sometimes obliges researchers to use methods yielding inferior results. At other times, soil characteristics destroy skeletal tissues, animal activity may result in missing and/or damaged elements, and poor excavation techniques may mean that skeletal components cannot be properly recovered. Animal-related processes include trampling, entrance fall, gnawing, and digestion. Physical factors include rock-fall, water transport, sandblasting, weathering, burial, diagenetic movement, volcanic shockwave, acid attack by roots, cryoturbation, release and breakup by bottom-fast ice, and mineralization by ground water (Marshall, 1989). All of these can act independently or in unison to produce alteration of bones. Additional taphonomic biases result from differential burial practices, sometimes leading to missing or under-represented age groups. Secondly, external factors such as differences between population groups, nutrition, disease, life-style and socio-economic status have all been shown to influence the rate of bone turnover in old adults. This interplay between intrinsic and extrinsic factors confounds age estimation and hampers contextual archaeological research such as palaeodemography (Jackes, 2000).

The most important results of the present work, which corroborates previous studies (e.g. Wittwer-Backofen et al., 2008), is the fact that small degrees of error are exclusively found in younger adults, due to the low individual variability of morphological ageing traits during childhood and early adulthood. However, in individuals whose mean ages are higher than 45-50 years, a lower degree of concordance between applied methods is observed. In this age range, due to the same nature of human senescence, characterised by an accumulation of metabolic disorders, morphological methods of age estimation do not offer sufficiently accurate results. The level of reliability and accuracy may vary from one study to another, but no reliable method 


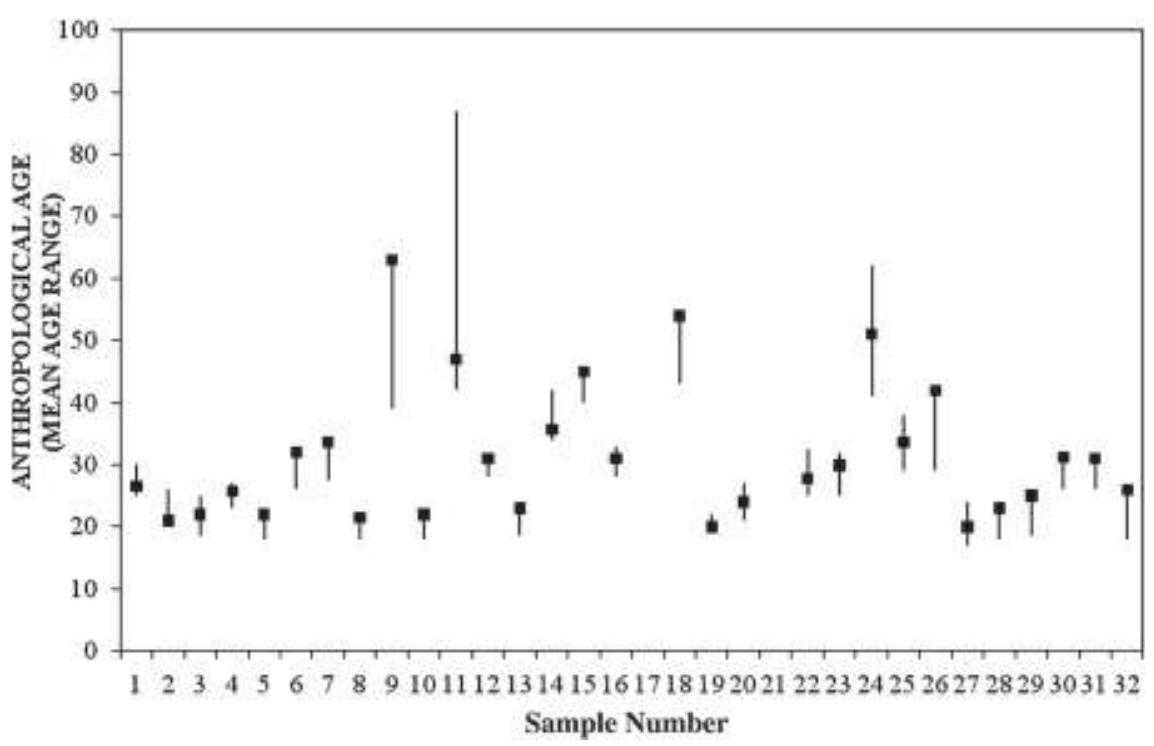

Fig. 5. Plots of canine dental age at death of the Spanish Medieval sample in the Islamic necropolis of La Torrecilla (black dots), overlaid with an indicator of mean age range estimated by anthropological methods.

seems to exists yet (Buckberry and Chamberlain, 2002; Meindl and Russel, 1997).

This study shows that age determination through study of the apposition of secondary dentine is a method consistent with the others and in most cases matches the results achieved by anthropological methods. Thanks to the position of the dentine inside the pulp cavity, which acts like an armour, taphonomic factors such as water, fire, chemical substances and micro-organisms do not affect internal examination of the tooth. The radiographic images of the teeth show greater contrast and there is a lower possibility of overlap. In addition, measurements of pulp and tooth areas on digital peri-apical images of canines yield more reliable and reproducible data than those achieved by orthopantomograms (Cameriere et al., 2004). In the present study, when pulp and tooth areas were measured on digital X-Ray images of both upper and lower canines, the concordance correlation coefficient showed that there were no significant intra-observer or inter-observer differences.

It is clear that, depending on the degree of preservation of each skeletal sample, Cameriere's method is not only a useful technique to assess the chronological age of living persons (Cameriere et al., $2007 a, b)$ but also that it is a reliable tool in determining age at death in historical skeletal remains. The method does not involve destruction or damage to teeth. In addition, although alterations in the pulp cavity may be detected in some ancient populations, indicating that diagenetic changes have taken place, such changes do not substantially affected the relation between apposition of secondary dentine and age at death.

Of the many dental methods of age estimation, the progressive diminution of the tooth pulp cavity has received far less research attention than other promising methods of age estimation (Rösing and Kvaal, 1998). As Cunha et al. (2009) noted, other dental

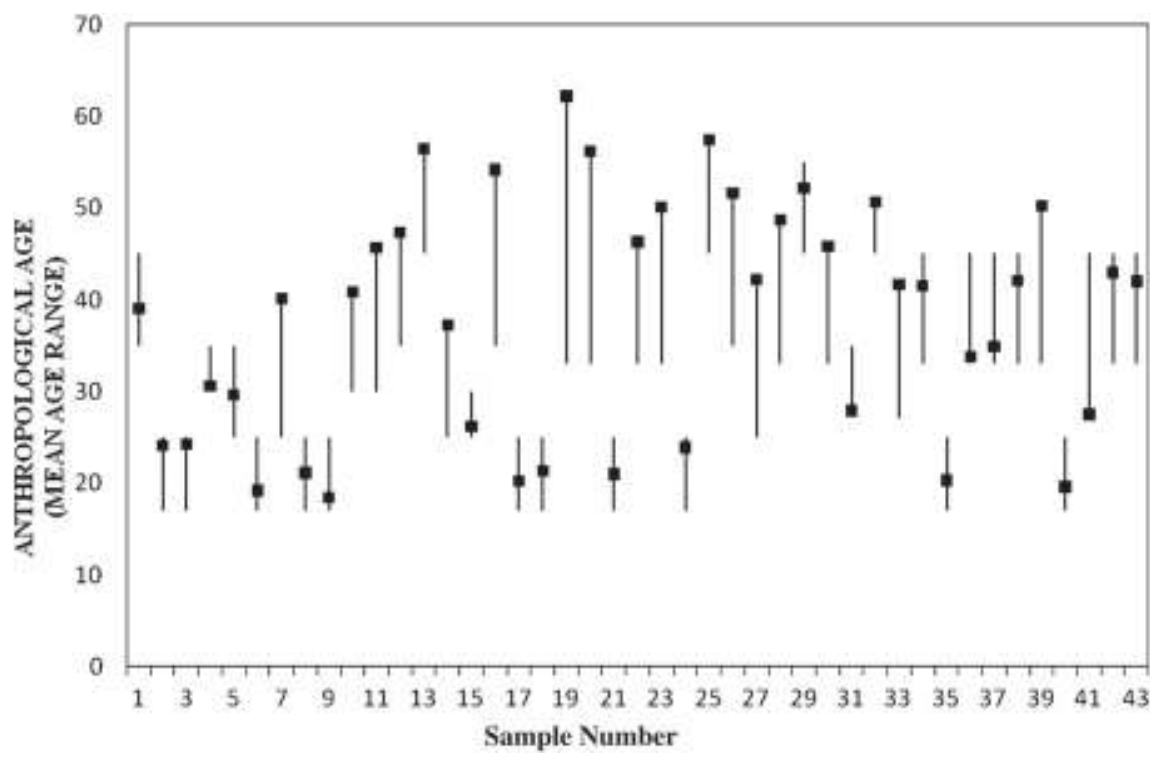

Fig. 6. Plots of dental canine age at death of the Italian Medieval samples in the cemeteries of Castel San Pietro and Comacchio (black dots) overlaid with an indicator of mean age range estimated by applying techniques based on dental wear and structure of pubic symphysis. 
methods such as that of Lamendin et al. (1993) or cementum annulation (Kagerer and Grupe, 2001) are not recommended for identifying ancient skeletal remains. These technique have been tested unsuccessfully on samples which had been buried in soil for several decades and they should be used with caution on historical samples (Griffin et al., 2009; Megyesi et al., 2006; Roksandic et al., 2009; Rosing et al., 2007). The applicability and the reliability of cementum annulation has also been seriously questioned (Renz and Radlanski, 2006). Several limitations have also been observed in analysis of dental wear (Brothwell, 1989), in which physiological and pathological elements both contribute to dental structure degeneration with ageing. Applying attrition as the only parameter may yield great deviations from the true age if, for instance, the person has had an abnormal occlusion or an unusual dental habit, which would cause greater attritional damage than normal. Brothwell's method should only be used as a general indicator of age and never as a technique of accurate estimation.

As regards the age estimation of older subjects, it is still necessary to test Cameriere's method in large samples of known age and sex, in order to determine whether the technique is applicable in terms of accuracy and also to recognise the many types of biases associated with it. We must try to develop standards that balance statistical effectiveness with wide-scale applicability.

\section{Conclusions}

Reliable age at death estimation of archaeological human remains is considered imperative in order to interpret osteological data within a biocultural framework. However, conventional osteological methods of age estimation in adult skeletons are fraught with problems, so that the findings of this study further highlight such difficulties. If the human skeletal remains are in fairly good state of preservation and complete in their "most diagnostic parts", normally employed macroscopical methods are adequate for a fairly good estimation, but if the skeletons are highly fragmented and incomplete, specific skeletal structures such as the pubic symphysis, auricular surface and sternal rib ends are often absent or too damaged for proper analysis. Depending on recovered components and taking into account the fact that the teeth are sometimes the only skeletal remains available, study of apposition of secondary dentine offers numerous advantages: it has been shown to provide a reliable age at death estimate and may help to narrow an estimate when used in combination with other morphological markers.

In this work, Cameriere's method (Cameriere et al., 2007a,b) was applied to an archaeological sample of individuals coming from three Spanish and Italian medieval cemeteries, in order to test its reliability in ancient skeletal remains. The results indicate the following:

1. The true age of the skeletal samples in the study was not known and, due to several confounding effects, the affect of particular influencing factors on age estimation could not be quantified. One key factor, for the choice of the appropriate method for ageing adult remains, is the quality of the preservation of these remains; dealing with a well-preserved entire body is a completely different problem than trying to age fragmented body parts.

2. It is evident from our results that different approaches may lead to significantly different mean age estimations and/or age ranges for each skeleton analysed. Depending on the number of applicable indicators of age, their consistency, and other factors, individual age ranges may vary significantly. Both the number and selection of age indicators, and the state of preservation may influence final palaeodemographic reconstruction. Furthermore, this study confirms that, when ascertaining the age of a skeleton, a multivariate approach is far more accurate than using one method alone (Martrille et al., 2007).

3. The appropriateness of using tooth/pulp area ratio (Cameriere et al., 2007a,b) as morphological variable to predict individual ages, especially when comparing obtained age estimates with other skeletal age calculation techniques based on, for example, cranial suture, pubic symphysis, auricular surface of the ilium or sternal rib ends.

4. Study of the apposition of secondary dentine is easy to apply, is not destructive, is more easily to check scientifically, is less dependent on technical ability than other techniques, and does not require highly specialised equipment (Cameriere et al., 2007a,b; Kvaal and Solheim, 1994). Some methods are very complex and/or destructive, and are not therefore normally used in anthropology. Also, they are often qualitative and require great technical expertise.

5. As noted in previous works (e.g., Cameriere et al., 2007a,b; Murray et al., 2002), the apposition of secondary dentine is not sex-dependent. Other anthropological indicators, such as the pubic symphysis, auricular surface of the ilium or metamorphosis of sternal rib ends depend on sex, which is not always easily diagnosed in archaeological material or in younger individuals.

6. Analysis of dental wear was the method most widely used in this study. However, tooth wear is highly dependent on too many variables such as attrition, diet and occlusion; loss of teeth may depend on social habits or infections and diseases (not necessarily will an edentulous mouth belong to an old individual, although it is more probable that it does).

Future research should aim at acquiring even larger sample sizes in order to reduce standard errors of estimates in older subjects and at testing the technique in more ancient samples, for which the influence of taphonomic factors and pathologies, such as wear or decay of one or several teeth, may be much more significant.

\section{Acknowledgements}

We thank two anonymous reviewers for their useful comments and suggestions, which improved the original version of this paper. We also want to thank Prof. Dr. Miguel C. Botella López for garanting the access to the Spanish osteological collection, Miriam Pérez de los Ríos for her English review and Dr. Candela Reyes Botella for providing X-ray machine.

\section{References}

Adams, B.J., Byrd, J.E., 2002. Interobserver variation of selected postcranial skeletal measurements. Journal of Forensic Sciences 47 (6), 1193-1202.

Aykroyd, R.G., Lucy, D., Pollard, A.M., Solheim, T., 1997. Technical note: regression analysis in adult age estimation. American Journal of Physical Anthropology 104, 259-265

Baccino, E., Tavernier, J.C., Lamendin, H., Frammery, D., Nossintchouk, R., Humbert, J.F., 1991. Recherche d'une méthode multifactorielle simple pour la détermination de l'âge des cadavres adultes. Journal de médecine légale droit médical 34, 27-33.

Belcastro, M.G., Rastelli, E., Mariotti, V., 2008. Variation of the degree of sacral vertebral body fusion in adulthood in two European modern skeletal collections. American Journal of Physical Anthropology 135, 149-160.

Bell, L.S., Skinner, M.F., Jones, S.J., 1996. The speed of post mortem change to the human skeleton and its taphonomic significance. Forensic Science International $82,129-140$.

Bertoldi, F., 2009. Gli Inumati. In: Gelichi, S. (Ed.), L'Isola del Vescovo. Gli scavi archeologici intorno alla Cattedrale di Comacchio, pp. 54-74.

Bodecker, C.F., 1925. A consideration of some of the changes in the teeth from young to old age. Dental Cosmos 67, 543-549.

Brothwell, D.R., 1989. The relationship of tooth wear to ageing. In: Iscan, M.Y. (Ed.), Age Markers in the Human Skeleton. Thomas, Springfield, IL, pp. 303-316. 
Buckberry, J.L., Chamberlain, A.T., 2002. Age estimation from the auricular surface of the ilium: a revised method. American Journal of Physical Anthropology 119, 231-239.

Cameriere, R., Ferrante, L., Cingolani, M., 2004. Variations in pulp/tooth area ratio as an indicator of age: a preliminary study. Journal of Forensic Sciences 49 (2), 1-3.

Cameriere, R., Brogi, G., Ferrante, L., Mirtella, D., Vultaggio, C., Cingolani, M., Fornaciari, G., 2006. Reliability in age determination by pulp/tooth ratio in upper canines in skeletal remains. Journal of Forensic Science 51, 861-864.

Cameriere, R., Ferrante, L., Belcastro, M.G., Bonfiglioli, B., Rastelli, E., Cingolani, M., 2007a. Age estimation by pulp/tooth ratio in canines by peri-apical X-rays. Journal of Forensic Sciences 52 (1), 166-170.

Cameriere, R., Ferrante, L., Belcastro, M.G., Bonfiglioli, B., Rastelli, E., Cingolani, M., 2007b. Age estimation by pulp/tooth ratio in canines by mesial and vestibular peri-apical X-rays. Journal of Forensic Sciences 52 (5), 1151-1155.

Cattaneo, C., 2007. Forensic anthropology: development of a classical discipline in the new millennium. Forensic Science International 165, 185-193.

Cunha, E., Baccino, E., Martrille, L., Ramsthaler, F., Prieto, J., Schuliar, Y., Lynnerup, N., Cattaneo, C., 2009. The problem of ageing human remains and living individuals: a review. Forensic Science International 193, 1-13.

Dedouit, F., Bindel, S., Gainza, D., Blanc, A., Joffre, F., Roug, D., Telmon, N., 2008. Application of the Iscan method to two- and three-dimensional imaging of the sternal end of the right fourth rib. Journal of Forensic Sciences 53 (2), 288-295.

Drusini, A.G., Toso, O., Ranzato, C., 1997. The coronal pulp cavity index: a biomarker for age determination in human adults. American Journal of Physical Anthropology 103, 353-363.

Ferembach, D., Schwidetzky, J., Stloukal, M., 1980. Recommendations for age and sex diagnoses of skeletons. Journal of Human Evolution 9, 517-549.

Galera, V., Ubelaker, D.H., Hayek, L.C., 1998. Comparison of macroscopic cranial methods of age estimation applied to skeletons from the Terry collection. Journal of Forensic Sciences 43, 933-939.

González, G., 2007. Determinación de la edad en adultos mediante un método dental. Aplicación y análisis. Tesis doctoral, Universidad de Granada (España).

Griffin, R.C., Chamberlain, A.T., Hotz, G., Penkman, K.E.H., Collins, M.J., 2009. Age estimation of archaeological remains using amino acid racemization in dental enamel: a comparison of morphological, biochemical, and known ages-atdeath. American Journal of Physical Anthropology 140, 244-252.

Gustafson, G., 1950. Age determinations on teeth. Journal of American Dental Association 41, 45-54.

Haglund, W.D., Sorg, M.H., 2002. Advances in Forensic Taphonomy. Method, Theory and Archaeological Perspectives. CRC Press, Boca Raton.

Hoppa, R.D., Vaupel, J.W., 2002. Paleodemography: Age Distributions from Skeletal Samples (Cambridge Studies in Biological and Evolutionary Anthropology 31). Cambridge University Press, Cambridge.

Igarashi, Y., Uesu, K., Wakebe, T., Kanazawa, E., 2005. New method for estimation of adult skeletal age at death from the morphology of the auricular surface of the ilium. American Journal of Physical Anthropology 128, 324-339.

Isscan, M.Y., Loth, S., 1989. Osteological manifestation of age in the adult. In: Isscan, M.Y., Kennedy, K.A.R. (Eds.), Reconstruction of Life from the Skeleton. Wiley-Liss, New York, NY, pp. 23-40.

Jackes, M., 2000. Building the bases for paleodemographic analysis: adult age determination. In: Katzenberg, M.A., Saunders, S.R. (Eds.), Biological Anthropology of the Human Skeleton. Wiley-Liss, Inc., New York, pp. 417-466.

Kagerer, P., Grupe, G., 2001. Age at death diagnosis and determination of life-history parameters by incremental lines in human dental cementum as an identification aid. Forensic Science International 118 (1), 75-82.

Kemkes-Grottenthaler, A., 2002. Ageing through the ages: historical perspectives on age indicator methods. In: Hoppa, R.D., Vaupel, J.W. (Eds.), Paleodemography: Age Distributions from Skeletal Samples (Cambridge Studies in Biological and Evolutionary Anthropology 31). Cambridge University Press, Cambridge, pp. $48-72$.

Kim, Y.K., Kho, H.S., Lee, K.H., 2000. Age estimation by occlusal tooth wear. Journal of Forensic Sciences 45 (2), 303-309.

Komar, D.A., Buikstra, J.E., 2008. Forensic Anthropology: Contemporary Theory and Practice. Oxford University Press, New York.

Konigsberg, L.W., Frankenberg, S.R., 2002. Deconstructing death in paleodemography. American Journal of Physical Anthropology 117, 297-309.

Kvaal, S.I., Solheim, T., 1994. A non-destructive dental method for age estimation. Journal of Forensic Odontostomatology 12 (1), 6-11.

Lamendin, H., Baccino, E., Humpert, J.F., Tavernier, J.C., Nossintchouk, R.M., Zerilli, A 1993. A simple technique for age estimation in adult corpses: the two criteria dental method. Journal of Forensic Sciences 37 (5), 1373-1379.

Landa, M.I., Garamendi, P.M., Botella, M.C., Alemán, I., 2009. Application of the method of Kvaal et al. to digital orthopantomograms. International Journal of Legal Medicine 123 (2), 123-128.

Librenti, M., 2003. La necropoli bassomedievale. In: Ortalli, J. (Ed.), San Pietro prima del Castello. Gli scavi dell'ex-Cinema Teatro Bios a Castel San Pietro Terme (Bologna). All'Insegna del Giglio, Firenze, pp. 54-61.

Lovejoy, C.O., 1985. Dental wear in the Libben population: its functional pattern and role in the determination of adult skeletal age at death. American Journal of Physical Anthropology 68 (10), 47-56.

Lovejoy, C.O., Meindl, R.S., Pryzbeck, T.R., Mensforth, R.P., 1985. Mensforth chronological metamorphosis of the auricular surface of the ilium. A new method for the determination of adult skeletal age at death. American Journal of Physical Anthropology 68 (1), 15-28.
Lucy, D., Pollard, A.M., Roberts, C.A., 1995. A comparison of three dental techniques for estimating age at death in humans. Journal of Archaeological Science 22, 417-428.

Maples, W.R., 1989. The practical application of age-estimation techniques. In: Isscan, M.Y. (Ed.), Age Markers in the Human Skeleton. Charles C. Thomas, Springfield, pp. 319-324.

Marshall, L.G., 1989. Bone modification and "the laws of burial". In: Bonnichsen, R., Sorg, M.H. (Eds.), Bone Modification. Center for the Study of the First Americans, Orono, ME, pp. 7-24

Martín de las Heras, S., Valenzuela, A., Villanueva, E., 1999. Deoxypyridinoline crosslinks in human dentine and estimation of age. International Journal of Legal Medicine 112, 222-226.

Martín de las Heras, S., 2005. Estimación de la edad a través del estudio dentario. Ciencia forense 7, 69-90.

Martrille, L., Ubelaker, D., Cattaneo, C., Seguret, F., Tremblay, M., Baccino, E., 2007. Comparison of four skeletal methods for the estimation of age-at-death in white and black adults. Journal of Forensic Sciences 52, 302-307.

Mays, S., 2003. The Archaeology of Human Bones. Routledge, London, New York.

Megyesi, M.S., Ubelaker, D.H., Sauer, N.J., 2006. Test of the Lamendin ageing method on two historic skeletal samples. American Journal of Physical Anthropology 131, 363-367.

Meindl, R.S., Lovejoy, C.O., 1985. Ectocranial suture closure: a revised method for the determination of skeletal age at death based on the lateral-anterior sutures. American Journal of Physical Anthropology 68 (1), 57-66.

Meindl, R.S., Russel, K.F., 1997. Recent advances in method and theory in paleodemography. Annual Review of Anthropology 27, 375-399.

Murray, P.E., Stanley, H.R., Matthews, J.B., Sloan, A.J., Smith, A.J., 2002. Age-related odontometric changes of human teeth. Oral Surgery, Oral Medicine, Oral Pathology, Oral Radiology and Endodontics 93, 474-482.

Ohtani, S., 1991. Age estimation using the racemization of aminoacid in human dentin. Journal of Forensic Sciences 36, 792-800.

Paewinsky, E., Pfeiffer, H., Brinkmann, B., 2005. Quantification of secondary dentin formation from orthopantomograms, a contribution to forensic age estimation methods in adults. International Journal of Legal Medicine 119, $27-30$

Philippas, G.G., 1961. Influence of occlusal wear and age on formation of dentin and size of pulp chamber. Journal of Dental Research 40, 1186-1198.

Philippas, G.G., Applebaum, E., 1966. Age factor in secondary dentin formation. Journal of Dental Research 45, 778-789.

Philippas, G.G., Applebaum, E., 1967. Age changes in the permanent upper lateral incisor. Journal of Dental Research 46, 1002-1009.

Philippas, G.G., Applebaum, E., 1968. Age changes in the permanent upper canine teeth. Journal of Dental Research 47, 411-417.

Prieto, J.L., 2002. Datos biológicos aportados por los dientes. El proceso de necroidentificación odontológica. In: Fundación Mapfre Medicina (Ed.), Antropología y Paleontología dentarias Madrid.

Renz, H., Radlanski, R.J., 2006. Incremental lines in root cementum of human teeth - a reliable age marker? Journal of Comparative Human Biology 57, $29-50$.

Roksandic, M., Dejana, V., Schillaci, M.A., Voicu, D., 2009. Technical note: applicability of tooth cementum annulation to an archaeological population. American Journal of Physical Anthropology 140, 583-588

Rösing, F.W., Kvaal, S.I., 1998. Dental age in adults. A review of estimation methods. In: Alt, K.W., Rösing, F.W., Teschler-Nicola, M. (Eds.), Dental Anthropology. Springer, Wien, pp. 443-468

Rosing, F.W., Graw, M., Marré, B., Ritz-Timme, S., Rotschild, M.A., Rotzscher, K., Schmeling, A., Schroder, I., Geserick, G., 2007. Recommendations for the forensic diagnosis of sex and age from skeletons. Homo 58 (1), 75-89.

Scheuer, L., Black, S., 2000. Developmental Juvenile Osteology. Academic Press, London.

Schmeling, A., Geserick, G., Reisinger, W., Olze, A., 2007. Age estimation. Forensic Science International 165, 178-181.

Solheim, T., 1992. Amount of secondary dentine as an indicator of age. Scandinavian Journal of Dental Research 100, 193-199.

du Souich, P., 1979. Estudio antropológico de la necrópolis medieval de La Torrecilla (Arenas del Rey, Granada). Antropología y Paleoecología Humana 1, 27-40.

Suchey, J.M., Katz, D., 1998. Application of pubic age determination in a forensic setting. In: Reichs, K.J. (Ed.), Forensic Osteology. Advances in Identification of Human Remains. C.C. Thomas Publisher, Springfield, Illinois, pp. 204-236.

Todd, T.W., 1921. Age changes in the pubic bone. American Journal of Physical Anthropology 4, 1-70.

Ubelaker, D.H., 1999. Human Skeletal Remains. Excavation, Analysis, Interpretation. Taraxacum, Washington.

Vasiliadis, L., Darling, A.I., Levers, B.G.H., 1983. The amount and distribution of sclerotic human root dentine. Archives of Oral Biology 28 (7), 645-649.

Wittwer-Backofen, U., Buckberry, J., Czarnetzki, A., Doppler, S., Grupe, G., Hotz, G., Kemkes, A., Larsen, C.S., Prince, D., Wahl, J., Fabig, A., Weise, S., 2008. Basics in Paleodemography: a comparison of age indicators applied to the early medieval skeletal sample of Lauchheim. American Journal of Physical Anthropology 137, 384-396.

Wood, J.W., Milner, G.R., Harpending, H.C., Weiss, K.M., 1992. The osteological paradox: problems of inferring prehistoric health from skeletal samples. Current Anthropology 33 (4), 343-370. 